\title{
BMJ Open Ultrasonographic reference values for peripheral nerves and nerve roots in the normal population of children and adolescents: study protocol for an observational-prospective trial
}

\author{
Maria Rasenack, ${ }^{1}$ Bernhard F Décard, ${ }^{1}$ Sabine Schädelin, ${ }^{2}$ Alexander Grimm, ${ }^{3}$ \\ Dirk Fischer, ${ }^{4,5}$ Patricia Hafner ${ }^{4,5}$
}

To cite: Rasenack M, Décard BF, Schädelin S, et al. Ultrasonographic reference values for peripheral nerves and nerve roots in the normal population of children and adolescents: study protocol for an observationalprospective trial. BMJ Open 2016;6: 014662.

doi:10.1136/bmjopen-2016014662

- Prepublication history for this paper is available online. To view these files please visit the journal online (http://dx.doi.org/10.1136/ bmjopen-2016-014662).

Received 17 October 2016 Revised 14 November 2016 Accepted 16 November 2016

CrossMark

For numbered affiliations see end of article.

Correspondence to Dr Maria Rasenack; maria. rasenack@usb.ch

\section{ABSTRACT}

Background: High-resolution ultrasonography is a new and promising technique to evaluate peripheral and spinal nerves. Its validity as a diagnostic tool in neurological diseases has been demonstrated in adults. Up to now no reference values have been published in children and adolescents although this technique would be ideal in this population as it is fast and noninvasive.

Methods/design: Our aim is to generate ultrasonographic reference values for several peripheral nerves (median, ulnar, radial, tibial, sural, peroneal and tibial nerve) as well as for the spinal nerves $\mathrm{C} 5$ and $\mathrm{C} 6$ and the vagus nerve in children and adolescents. In an observational prospective study, we will recruit 205 children and adolescents aged between $\geq 2$ and $\leq 18$ years without neuromuscular symptoms/signs and without a history of neuromuscular disease. After the collection of demographic and anthropometric data (height, weight, body mass index, age, gender and handedness) and a neurologic examination, a highresolution ultrasonography of peripheral and spinal nerves at several anatomic landmarks will be performed. These data will be used to estimate agedependent percentile curves and to evaluate inter-rater, intrarater and interequipment reliability of the measurements.

Ethics and dissemination: This study was approved by the local ethics committee (EKNZ 2015-210). The findings from this study will be disseminated through peer-reviewed publications and conference presentations. Trial registration number: NCT02570802, pre-results publication.

\section{BACKGROUND}

High-resolution ultrasonography is an emerging non-invasive technique for the investigation of peripheral nerves and is increasingly used worldwide in the diagnosis of peripheral nerve disorders. The value of peripheral

\section{Strengths and limitations of this study}

- Sample size estimation is based on measurements from pilot data.

- The estimated sample size of 200 patients allows to estimate the $50 \%$ percentile curve for crosssectional areas of the most examined nerves at different clinically important locations with adequate accuracy.

- Monocentric study.

- Unrecognised confounders could potentially alter our measurements.

nerve ultrasound for diagnosis of peripheral nerve damage in entrapment syndromes, nerve tumours and focal nerve lesions has been demonstrated clearly. ${ }^{1-9}$ In adults, it has become a useful supplementary tool for electrodiagnostic studies in these conditions. Characteristic nerve size changes in polyneuropathies have been reported as well ${ }^{10-16}$ and are now further investigated. Nerve width (medial to lateral diameter), thickness (anterior to posterior diameter) and crosssectional area (CSA) measured on transverse scans, and anteroposterior diameter measured on longitudinal scans are the most frequently used quantitative parameters for the ultrasound investigation of peripheral nerves. Furthermore, ratios of CSA between different segments of the same nerve have also been used. Several reports have been published on reference values for the CSAs in nerves in adulthood, as well as normal values for cervical roots, radial nerve, lower limb nerves and pure sensory nerves. ${ }^{17-22}$ In children, the use of ultrasound was demonstrated in few studies of hereditary and immunemediated neuropathies. ${ }^{23}{ }^{24}$ So far no work has been published on standard values for 
ultrasonography in children and adolescents. Especially in this population, benefit of this fast and non-invasive technic is great because children can be examined much more stress free. The aim of our study is to establish normal CSA values for C5 and C6 cervical roots, and several upper and lower limb nerves, including some pure sensory nerves, at predefined anatomical sites in children and adolescents and to assess whether the CSAs correlates with height, age, gender and body mass index (BMI). Furthermore, to test if such measurements are reliable in routine clinical practice, the intrarater and inter-rater reliability of peripheral nerve ultrasound measurements will be assessed.

\section{METHODS/DESIGN}

Objectives and end points

The purpose of this study is to assess standard values of nerve ultrasonography in children and adolescents to use these values as a reference in clinical practice. This allows that nerve ultrasonography in children can be further evaluated and compared with standard values in different diseases as it has been done in adults. The primary end point is to determine standard values of the CSA of the C5 and C6 cervical roots, the vagus, median, ulnar, radial, superficial radial, peroneal, tibial and the sural nerves in children and adolescents between $\geq 2$ and $\leq 18$. The secondary objectives are (1) to determine relations between CSA and epidemiological data and (2) to assess inter-rater and intrarater reliability of measurements.

\section{Study design}

This is an observational prospective, monocentre study with an estimated duration of 12 months. The study was registered with ClinicalTrials.gov (identifier: NCT02570802).

\section{Inclusion criteria}

- Children and adolescents aged between $\geq 2$ and $\leq 18$ years.

- Written informed consent of the caregivers and the children/adolescents between 10 and 18 years.

- Oral assent by children under the age of 10 years.

\section{Exclusion criteria}

- Inability to meet study requirements.

- Neuromuscular disease or symptoms/signs.

\section{Methodology}

Children/adolescents that fullfill the inclusion criteria and their caregivers will be informed about the procedures and asked to participate directly after a routine consultation in the outpatients' department, during a hospitalisation at the University of Basel Children's Hospital (UKBB), per written letter addressed to school classes or sports clubs and from the authors' circle of acquaintances and colleagues. Demographic and anthropometric data are collected (height, weight, BMI, age, gender and handedness) and a neurologic examination is performed. Inclusion and exclusion criteria are verified. If the criteria are met, the child will be enrolled into the study (table 1).

Most of the children are examined once for about $60 \mathrm{~min}$ by one examiner. A number of 47 participants will be examined twice. Of these, 19 children will be examined again by the same examiner (intrarater reliability), 28 children by another examiner (inter-rater reliability). The second examiner will be blinded to the results of the first examination.

\section{Assessments of primary end point/outcome}

Ultrasound measurements will be done in different nerves and at different locations. Ultrasound is performed using a high-frequency probe real-time linear array scanner (Philipps Affiniti 50G and others). Ultrasound of different nerves at the upper and lower limbs and the neck are performed bilaterally. The nerves are scanned in axial planes, and the CSA of each nerve is measured at standardised anatomical points as described before. ${ }^{25}$ In short: median nerve in the midupper arm, at the elbow, in the mid-forearm and at the carpal tunnel; ulnar nerve at mid-humerus, at the cubital tunnel and in the mid-forearm; radial nerve in the mid-upper arm and superficial radial as well as posterior interosseous nerve at the supinator loge; peroneal nerve in the popliteal space and at the fibular head; tibial nerve in the popliteal space and at the medial malleolus and sural nerve between lateral and medial gastrocnemic head in the calf. In addition, the vagus nerve is analysed at the lateral margins of the anterior cervical region beneath the sternocleidomastoid muscle and the diameter and CSA of the 5th and 6th cervical nerve roots are measured in longitudinal scan below the processus transversus. CSA is traced inside the hyperechoic rim of the nerve (figure 1).

\begin{tabular}{lll} 
Table 1 Project flow chart & \\
\hline Project periods & $\begin{array}{l}\text { Screening } \\
\text { and visit }\end{array}$ & $\begin{array}{l}\text { Possible } \\
\text { extra visit }\end{array}$ \\
\hline Visit & 1 & 2 \\
Time & 60 min & 60 min \\
Participant information & $\mathrm{x}$ & \\
$\begin{array}{l}\text { and informed consent } \\
\text { Demographics }\end{array}$ & $\mathrm{x}$ & \\
$\begin{array}{l}\text { Anthropometric } \\
\text { measurements (weight, }\end{array}$ & $\mathrm{x}$ & \\
$\begin{array}{l}\text { age) } \\
\text { Medical history }\end{array}$ & $\mathrm{x}$ & \\
$\begin{array}{l}\text { Clinical examination } \\
\text { Inclusion/exclusion }\end{array}$ & $\mathrm{x}$ & $\mathrm{x}$ \\
criteria & $\mathrm{x}$ & \\
Ultrasound (see list & $\mathrm{x}$ & $\mathrm{x}$ \\
below) & & \\
\hline
\end{tabular}




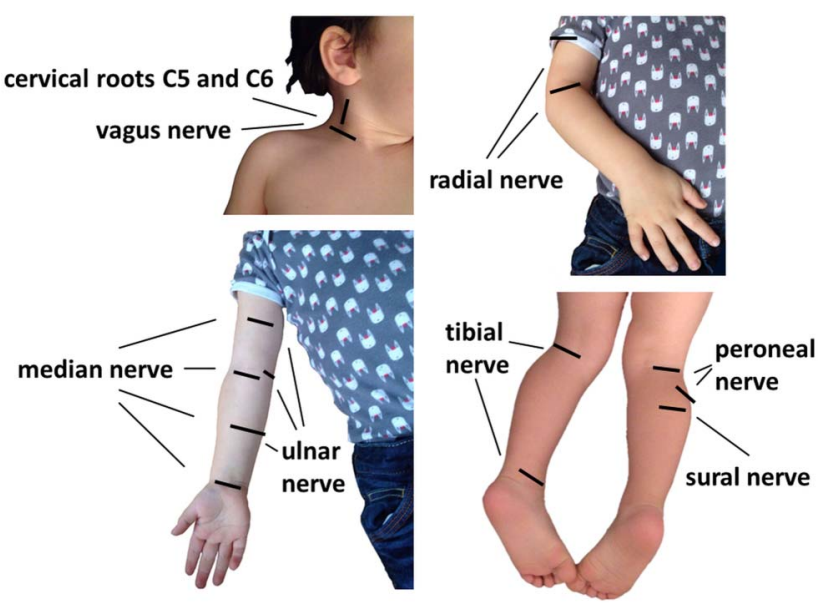

Figure 1 Standardised anatomical points for the measurement of CSA of the measured nerves and diameter of nerve roots.

\section{Assessment of secondary end points}

Epidemiological data will be measured before performing the ultrasonographic examination. Height and weight are measured, BMI is calculated. The patient or the caregiver is asked about the age (date of birth), gender and handedness.

\section{Statistics}

The sample size was calculated in order to estimate the percentile curves with adequate accuracy. The accuracy of the estimation was quantified by the length of the bootstrapped $95 \%$ CI of the $50 \%$ percentile curve. The sample size estimation was based on the measurements of medianus prox. forearm right side from the pilot data. Twelve patients between age 3.75 and 6.25 were used in this sample size estimation using a resampling method. Each sample size was evaluated by estimating the $50 \%$ percentile curve together with its bootstrapped 95\% CI R=100 times. Each 95\% CI was estimated by simulating 99 times in individual patients, fitting a "Generalised additive model for location, scale and shape" and estimating the $50 \%$ percentile curve from the fitted model. Then the $95 \%$ CI of the $50 \%$ percentile curve was estimated using a bootstrap approach using these 99 estimations. For each $50 \%$ percentile curve, it was assessed whether the length of the 95\% CI was below the predefined margin of 1.2. Assuming a dropout rate of $2 \%, 205$ patients should be recruited to ensure 200 evaluable patients. This sample size allows in more than $80 \%$ of 100 hypothetical repetitions of the study (ie, with a power of 0.8 ) to estimate the $50 \%$ percentile curve with adequate accuracy (length of the $95 \%$ CI below the predefined margin of 1.2). Figure 2 shows how the sample size depends on the predefined accuracy threshold of the estimate. Additional sample size estimation was performed in order to estimate the sample size needed to estimate the inter-rater and intrarater reliability of the measurements. Reliability is expressed by the intraclass correlation coefficient (ICC).

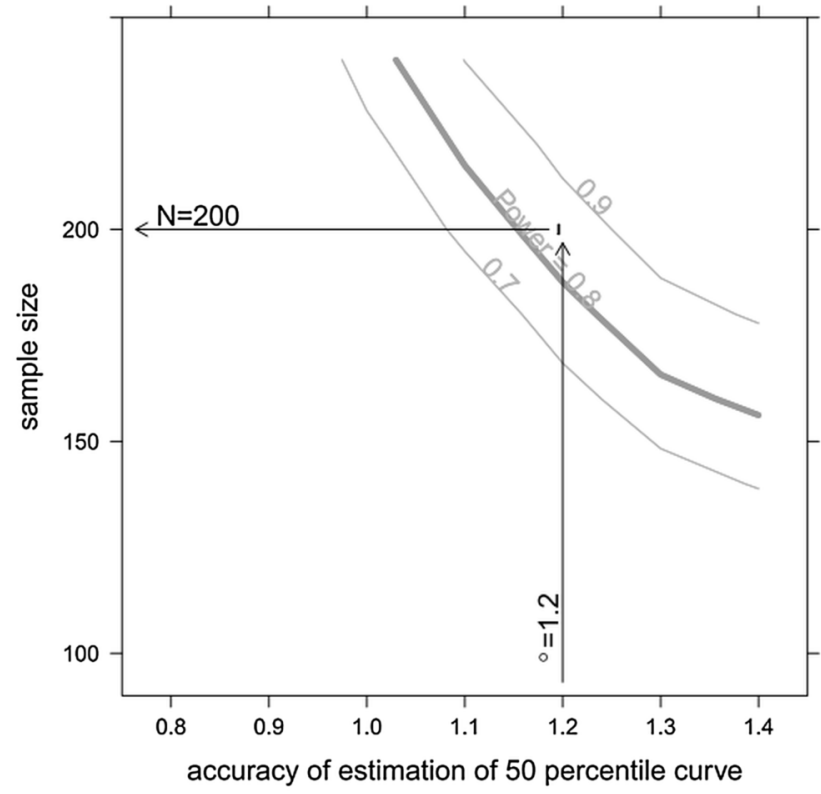

Figure 2 Sensitivity of the sample size with respect to the predefined accuracy threshold of the estimate. The curves for a power of $0.7,0.8$ and 0.9 (ie, $70 \%, 80 \%$ and $90 \%$ ) are shown. (The curves are smoothed and are shown for illustrative purposes only).

Two scenarios have been calculated assuming two examinations in each child with different ICC for intrarater and inter-rater reliability. It is assumed that the ICC is 0.8 for intrarater and 0.75 for inter-rater reliability. The study should be able to estimate the ICC with a certain precision. This precision is expressed as the width of a 95\% CI and is here defined to be one-third. By applying the sample size approximation of Bonett ${ }^{26}$ and assuming a dropout rate of $5 \%$, a sample size of 20 patients results (value rounded to the next higher integer) when assuming each child is examined twice for intrarater reliability (figure 3). A sample size of 30 results when assuming each child is examined twice for inter-rater reliability (figure 4).

Figures 3 and 4 show how the sample size depends on the assumed ICC and the number of examinations in each child.

\section{Primary analysis}

The age-dependent percentile curves will be estimated using a "Generalised additive model for location, scale and shape" as suggested by the WHO Multicentre Growth Reference Study Group ${ }^{27}$ using the R-package Rigby and Stasinopoulos. ${ }^{28}$ The analysis will be performed on the full-analysis data set.

\section{Secondary analyses}

The same percentile curves as described in the main analysis will be estimated depending on size and weight. The models will be compared with the main model in order to investigate whether a growth curve in 
number of examinations in one child: 2

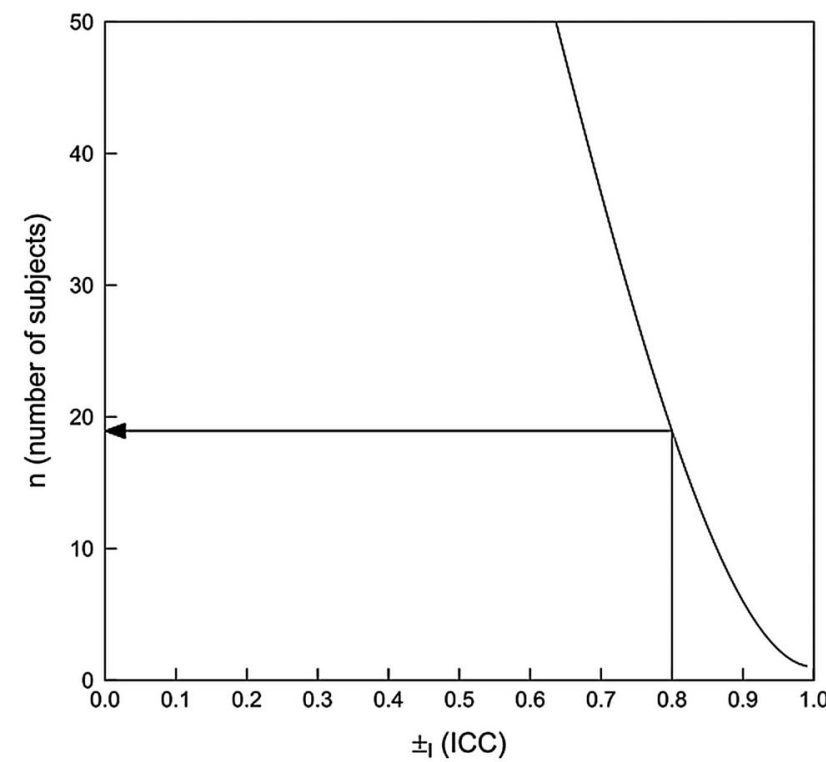

Figure 3 Sample size estimation for ICC—intrarater reliability. The curve for a power of 0.8 is shown.

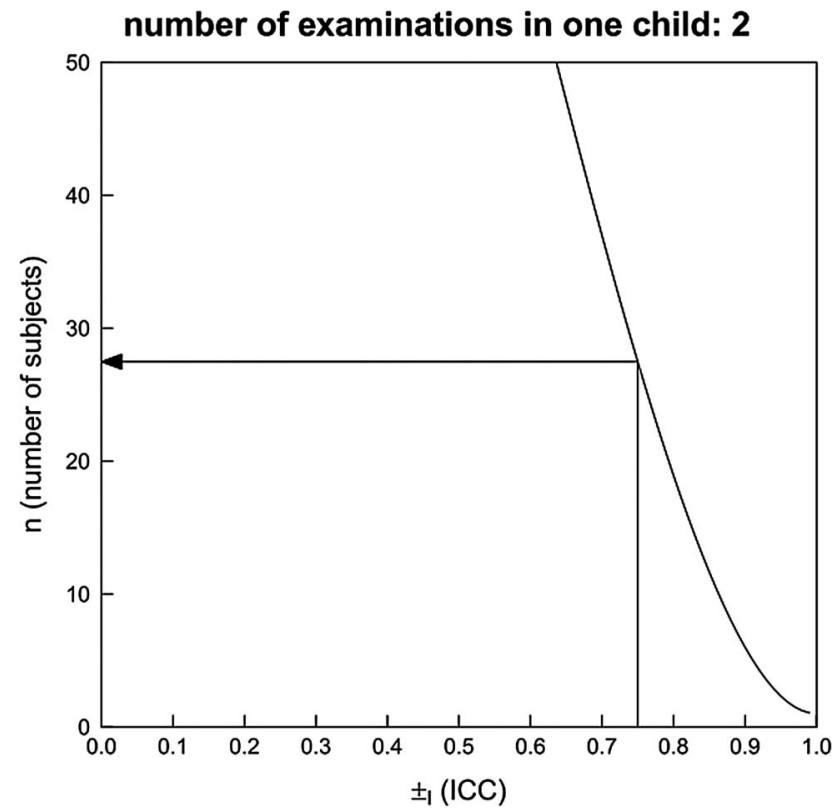

Figure 4 Sample size estimation for ICC-inter-rater reliability. The curve for a power of 0.75 is shown.

dependence of size or weight is more applicable than a growth curve depending on age. The association between gender and handedness and the thickness of the nerves will be investigated by including these variables as covariables in the main model in an exploratory manner. If gender has a relevant influence on thickness of the nerves, separate growth curves for each gender will be considered.

Inter-rater, intrarater and inter-equipment reliability of the measurements will be investigated by estimating ICCs according to Streiner and Norman. ${ }^{29}$
Data protection, archiving and destruction

In this study, personal patient data will be captured. These data will be encoded and are only accessible to experts. The appropriate experts of the sponsor (or their designees) can survey the conduct of the study with monitoring or audits. In case of inspections, these experts and also members of the appropriate authorities can get access to the original data. Also the responsible Ethics Committee can get access to the original data. The confidentiality of the data will be strictly protected during the whole study and when performing the mentioned controls. The name of the patient will not be published in no way in reports or publications arisen from the study.

The paper documents will be stored in a lockable room during 10 years in the archive of the UKBB in a dedicated shelf.

\section{Ethical considerations}

To generate ultrasonographic reference values in children and adolescents it is inevitable to include participants requiring particular protection (children under the age of 18 years) into this trial. The participation in this study is voluntary. The parents and the patient can withdraw their consent at every time point without giving any reason. In case of withdrawal, the data collected until this time point will be used.

As the ultrasonography of peripheral nerves is a noninvasive and painless examination, the benefit of generating normal values and therefore providing a tool to complement and minimise more invasive electrophysiological examinations legitimates the recruitment and examination of participants requiring particular protection.

The study is registered online with clinicaltrials.gov (NCT02570802).

\section{DISSEMINATION}

The results of this study will be published in peerreviewed journals and presented at national and international scientific meetings and congresses to ensure the applicability of its findings into clinical practice.

\section{DISCUSSION}

Standard values for nerve ultrasonography in children and adolescents have not been published so far. This fast and non-invasive technique may provide great benefit especially in children because they can be examined much more stress free. Therefore, the main aim of our study is to establish normal CSA values for C5 and C6 cervical roots, and several upper and lower limb nerves, including some pure sensory nerves, at predefined anatomical sites in children and adolescents. This study will provide these urgently needed reference values for the ultrasonographic evaluation of several peripheral and spinal nerves at specific anatomic landmarks in children and adolescents under the age of 19 years. 
These normal values will guide clinicians in examining children and adolescents with neuromuscular diseases by ultrasonography.

Strength: The sample size estimation was based on the available measurements from pilot data. Assuming a dropout rate of $2 \%, 205$ patients aged between 2 and 18 years should be recruited to ensure 200 evaluable patients. This sample size allows in more than $80 \%$ of 100 hypothetical repetitions of the study (ie, with a power of 0.8 ) to estimate the $50 \%$ percentile curve for CSAs of the most examined nerves at different clinically important locations with adequate accuracy.

Limitations: Even though we plan to include a large cohort there still is the possibility of unrecognised confounders. The trial is planned as a monocentric study. By not only including patients from our hospital but also from schools, sports classes and the authors' circle of acquaintances, we will try to reduce selection bias.

\section{Trial status}

The trial started enrolment in November 2015 and is expected to be completed by the end of December 2017.

\section{Author affiliations}

${ }^{1}$ Department of Neurology, Basel University Hospital, Basel, Switzerland

${ }^{2}$ Clinical Trial Unit, Basel University Hospital, Basel, Switzerland

${ }^{3}$ Department of Neurology, Tübingen University Hospital, Tübingen, Germany

${ }^{4}$ Division of Neuropaediatrics, University of Basel Children's Hospital, Basel,

Switzerland

${ }^{5}$ Division of Neurology, Medical University Clinic, Kantonsspital Baselland, Bruderholz, Switzerland

Contributors MR participated in the design of the study, acquired data and drafted the manuscript. BFD participated in the design of the study and acquired data. SS participated in the design of the study, performed the statistical analysis and calculated the sample size for the study. AG designed the study and acquired data. DF participated in the design of the study and revised the manuscript. PH designed and conducted the study, acquired data and revised the manuscript. All authors read and approved the final manuscript.

Competing interests None declared

Patient consent Obtained.

Ethics approval Ethikkommission Nordwest- und Zentralschweiz (EKNZ 2015-210).

Provenance and peer review Not commissioned; externally peer reviewed.

Open Access This is an Open Access article distributed in accordance with the Creative Commons Attribution Non Commercial (CC BY-NC 4.0) license which permits others to distribute, remix, adapt, build upon this work noncommercially, and license their derivative works on different terms, provided the original work is properly cited and the use is non-commercial. See: http:// creativecommons.org/licenses/by-nc/4.0/

\section{REFERENCES}

1. Peer S, Bodner G, Meirer R, et al. Examination of postoperative peripheral nerve lesions with high-resolution sonography. AJR Am J Roentgenol 2001;177:415-19.

2. Peer $S$, Kovacs $P$, Harpf $C$, et al. High-resolution sonography of lower extremity peripheral nerves: anatomic correlation and spectrum of disease. J Ultrasound Med 2002;21:315-22.
3. Kele H, Verheggen R, Bittermann $\mathrm{HJ}$, et al. The potential value of ultrasonography in the evaluation of carpal tunnel syndrome. Neurology 2003;61:389-91.

4. Gruber H, Glodny B, Bendix N, et al. High-resolution ultrasound of peripheral neurogenic tumors. Eur Radiol 2007;17:2880-8.

5. Zaidman CM, Pestronk A. Nerve size in chronic inflammatory demyelinating neuropathy varies with disease activity and therapy response over time: a retrospective ultrasound study. Muscle Nerve 2014;50:733-8.

6. Scheidl E, Bohm J, Simo M, et al. Different patterns of nerve enlargement in polyneuropathy subtypes as detected by ultrasonography. Ultrasound Med Biol 2014;40:1138-45.

7. Abraham A, Izenberg A, Dodig D, et al. Peripheral nerve ultrasound imaging shows enlargement of peripheral nerves outside the brachial plexus in neuralgic amyotrophy. J Clin Neurophysiol 2016;33:e31-3.

8. $\mathrm{Ng} \mathrm{ES,} \mathrm{Vijayan} \mathrm{J,} \mathrm{Therimadasamy} \mathrm{A,} \mathrm{et} \mathrm{al.} \mathrm{The} \mathrm{added} \mathrm{value} \mathrm{of}$ preoperative ultrasonography of the ulnar nerve: an observational study. Muscle Nerve 2010;42:613-4.

9. Samarawickrama D, Therimadasamy AK, Chan YC, et al. Nerve ultrasound in electrophysiologically verified tarsal tunnel syndrome. Muscle Nerve 2016;53:906-12.

10. Zaidman CM, Al-Lozi M, Pestronk A. Peripheral nerve size in normals and patients with polyneuropathy: an ultrasound study. Muscle Nerve 2009;40:960-6.

11. Imamura $\mathrm{K}$, Tajiri $\mathrm{Y}$, Kowa $\mathrm{H}$, et al. Peripheral nerve hypertrophy in chronic inflammatory demyelinating polyradiculoneuropathy detected by ultrasonography. Intern Med 2009;48:581-2.

12. Beekman $\mathrm{R}$, van den Berg $\mathrm{LH}$, Franssen $\mathrm{H}$, et al. Ultrasonography shows extensive nerve enlargements in multifocal motor neuropathy. Neurology 2005;65:305-7.

13. Padua L, Granata G, Sabatelli M, et al. Heterogeneity of root and nerve ultrasound pattern in CIDP patients. Clin Neurophysiol 2014;125:160-5.

14. Kerasnoudis A, Pitarokoili K, Behrendt V, et al. Nerve ultrasound score in distinguishing chronic from acute inflammatory demyelinating polyneuropathy. Clin Neurophysiol 2014;125:635-41.

15. Tanaka K, Ota N, Harada $\mathrm{Y}$, et al. Normalization of sonographical multifocal nerve enlargements in a MADSAM patient following a good clinical response to intravenous immunoglobulin. Neuromuscul Disord 2016;26:619-23.

16. Breiner A, Qrimli M, Ebadi $\mathrm{H}$, et al. Peripheral Nerve High-Resolution Ultrasound in Diabetes. Muscle Nerve 2016.

17. Cartwright MS, Shin HW, Passmore LV, et al. Ultrasonographic reference values for assessing the normal median nerve in adults. $J$ Neuroimaging 2009;19:47-51.

18. Boehm J, Scheidl E, Bereczki D, et al. High-resolution ultrasonography of peripheral nerves: measurements on 14 nerve segments in 56 healthy subjects and reliability assessments. Ultraschall Med 2014;35:459-67.

19. Heinemeyer O, Reimers CD. Ultrasound of radial, ulnar, median, and sciatic nerves in healthy subjects and patients with hereditary motor and sensory neuropathies. Ultrasound Med Biol 1999;25:481-5.

20. Won SJ, Kim BJ, Park KS, et al. Reference values for nerve ultrasonography in the upper extremity. Muscle Nerve 2013;47:864-71.

21. Haun DW, Cho JC, Kettner NW. Normative cross-sectional area of the C5-C8 nerve roots using ultrasonography. Ultrasound Med Biol 2010;36:1422-30

22. Qrimli M, Ebadi H, Breiner A, et al. Reference values for ultrasonograpy of peripheral nerves. Muscle Nerve 2016;53:538-44.

23. Almeida V, Mariotti $\mathrm{P}$, Veltri S, et al. Nerve ultrasound follow-up in a child with Guillain-Barre syndrome. Muscle Nerve 2012;46:270-5.

24. Yiu EM, Brockley CR, Lee KJ, et al. Peripheral nerve ultrasound in pediatric Charcot-Marie-Tooth disease type 1A. Neurology 2015;84:569-74.

25. Grimm A, Heiling B, Schumacher $U$, et al. Ultrasound differentiation of axonal and demyelinating neuropathies. Muscle Nerve 2014;50:976-83.

26. Bonett DG. Sample size requirements for estimating intraclass correlations with desired precision. Stat Med 2002;21:1331-5.

27. Borghi E, de Onis M, Garza C, et al. Construction of the World Health Organization child growth standards: selection of methods for attained growth curves. Stat Med 2006;25:247-65.

28. Rigby RA, Stasinopoulos DM. Generalized additive models for location, scale and shape. J Roy Stat Soc C-App 2005;54:507-44.

29. Streiner DL, Norman GR, Cairney J. Health measurement scales : a practical guide to their development and use. 5th edn. Oxford: Oxford University Press, 2015. 